\title{
Basics of Informed Logistics in Just-in-Time Production Sequencing and Supply Chain Systems
}

\author{
Gyan Bahadur Thapa \\ Institute of Engineering, Tribhuvan University, Kathmandu, Nepal \\ Corresponding email: thapagbt@ioe.edu.np
}

\begin{abstract}
Informed logistics is one of the quite recent and challenging research issues in the domain of supply chain production. The real-time information is taken as one of the productivity factor in all sort of business operations. In this paper, we present a very basic and brief literature of informed logistics together with the recent developments in this area. Observing information flows among logistics functions in production processes, we explain some information technology enablers of informed logistics. We propose an $A B S O$ model for better sharing and operation of information, and finally we indicate the applications of informed logistics in real-time scheduling.
\end{abstract}

Keywords: Logistics, supply chain, just-in-time, information flows

\section{Introduction}

This is the century of information technology (IT), which plays a key role in all business activities. Decision making, problem solving, commodity producing, knowledge performing and finished goods distributing are the intensive works of most of the companies today, which require readily available and suitable information. In today's highly competitive and dynamic society, information is considered as one of the important production factors besides capital and human resources. Finding the right information at the right time to support a business decision process is often very difficult task. Recent studies show that a growing number of business executives perceive information flow as a serious challenge in practice. The informed logistics (IL) investigates the approaches and solutions for an improved information supply for all kinds of distributed work environments, such as enterprises with several locations, networks of small and medium enterprises and mobile workforces. In this context, modeling and capturing information demand is a key element of $I L$ solutions. Logistic process itself is a crucial factor in all kinds of production and service operations. In fact, the logistics management is the process of planning, implementing and controlling the efficient, cost-effective flow and storage of raw materials, in-process inventory, finished goods and related information from point-of-origin to point-of-consumption targeting to meet requirements of customers [1]. The aim of $I L$ is to deliver the right information, in the right format, at the right place at the right time for the right people in a customer demand driven approach [2], known as a just-in-time (JIT) information distribution system. Gaining logistics information excellence in today's agile industrial scenario has become a boardroom level concern. Logistics performance leaders are building a significant advantage over the competition that leads to substantially better bottom line performance and increases shareholder value relying upon real-time information.

The focus of today's dynamic society has shifted from a manual labor society to an information society, where informed decision making has become one of the key productivity factors in business. Most of the organizations largely depend on knowledge and information, which have 
become part of their assets. Though information is widely made available, for instance by the evolution of the internet, it is harder to retrieve the right information in desired time. Knowledge workers in many organizations experience this troublesome paradox every day, whenever dealing with an information overload. On the other hand, they experience a lack of real-time information to support them with the task at hand. So certain structure is needed to deal with information flows among every node of organizations. The collection, distribution and aggregation of information are essential activities directly contributing to the business goals and should therefore be optimized as a part of the business process. A pre-requisite is the full availability, accessibility and the quality of the information to be delivered. However, present management systems have reached their limits: mass production is optimized but customized production is still not efficiently supported. It is one of the considerable challenges as well as a significant opportunity for research.

Information can be created throughout the entire span of logistics in the production process and re-used in a structured manner along the value creation chain. The aim of $I L$ is to optimize the content and format of available data to reduce throughput times and to achieve a high degree of parallel processing. This requires the use of an information model, an overall product tree and a graphic design concept. The deployed system must meet these requirements in optimal way. Upon these facts, $I L$ means to acquire desired data in real-time (i.e., being informed) and to apply them optimally as information and knowledge in production process making intelligent decisions in traffic flows including road, sea and air (i.e., data logistics). Every business which needs flexible, fast and quality decision making increasingly depends on knowledge and information driven by today's very competitive market demands. The developments in information and document management are required from the perspective of the user, and his/her abilities to serve the customer in the best way. The user of information has always been the driver of innovation, dealing with the four facets of information: input (data), storage, processing and output. The particular challenge is related to the efficient uses and movement of the huge amount of data that has been collected. Thus, ultimate goal of $I L$ is to gain real-time data and apply them to achieve maximum control and visibility of fleet and deliveries for better real-time decisions in favor of customers. So efficiently and effectively managed data and information exchange are becoming crucial along the logistics chain.

\section{Challenges and Developments}

The underlying success of logistics depends on the flow of data and information for effective management. For a systematic study of $I L$, it should be analyzed that what kinds of challenges and developments are faced and recognized by organizations these days [3]. Some challenging issues due to rapid changes in business management structures are:

- To produce more customer-oriented goods and services in a demand-driven approach.

- To be able to make quicker and better informed decisions for effective logistics management.

- To address the networked managerial structures and peer-to-peer relationships.

- To provide reliable information to the employees (knowledge workers) to carry out their job.

- To find new ways to improve logistics performance and customer value as a result of market pressure. 
- To understand and address customer choices and expectations, and to aware them in procurement of logistics services encouraging behavioral change.

- To optimize uses of the whole transport network for effective movement of goods, facilitating more sustainable approaches to rural, local, regional, national and international logistics.

Due to the increased capabilities of mobility through the technologies such as internet, telecom, computers etc, most of the manufacturing companies are now facing both pros and cons, such as availability of more information in higher amount than ever before, more access places for users than before, more widely spread but unstructured information as well as dramatically varied quality of information. On the other end, overflow of more information takes too much time in finding the right information, puts pressure on process efficiency and the productivity of employees, and makes process control difficult or impossible; and hence the availability of more information does not necessarily improve decision making speed and quality. As a result of these facts, organizations are challenged in both negative and positive ways. The negative side is: how to handle decision making and efficiency with the increasing information flow, and the positive side is: what kind of improvements can really create new customer value. It is a fact that today's organizations are confronted with more demanding customers desiring high quality products together with JIT information. If the organizations pay attention to the new opportunities presented by $I L$, they can reduce business risks, such as decreasing speed, inflexibility in decision making, productivity decrease, variable quality and errors in goods and service delivery, failing to comply with new rules and legal requirements, security issues, business processes which cannot cope with the required speed of operation. As the information landscape has become increasingly complex, companies face significant challenges to alter their way of working to cope with this new situation. But at the same time it opens tremendous new opportunities to create fresh customer values.

The development of $I L$ can be compared with two major developments in manufacturing that took place in previous decades, which significantly improved the business process. The first is the development of JIT systems for goods logistics which enhanced the system from supply-driven to more demand-driven. $I L$ is driving a similar change focusing from the supply-driven to a more demand-driven JIT usage of information. The second is development of industrial and system engineering, e.g., Goldratt's theory of constraints. Similar to the production bottlenecks in Goldratt's theory, constraints in the information world are mainly caused by the user who needs efficient JIT information to do his job. By solving those constraints, one can expect similar types of efficiency improvements and the acceleration of business processes with flexibility. In addition of keeping sight of their overall business goals, companies today need a very flexible, fast and efficient information supply for individual workers and decision makers. The required solution cannot be achieved by simply modeling and optimizing business processes, since further support is required at a task level within and across the business processes which means a deeper insight in information flows and demand on the job. The other challenges of $I L$ are time sensibility and perishable nature of the products.

The emerging aspect to manage $I L$ is the knowledge management $(K M)$, which is defined as the organizational design and operational principles, processes, applications and technologies that helps the knowledge worker to leverage creativity and creates the ability to add value to the business. $K M$ tries to resolve the paradox of massive data overloads dealing with the access and use of information which enables knowledge workers to apply information to what they already 
know and so create knowledge. The information is more valuable when it is transformed into knowledge by reading, understanding, interpreting and consequently applying it to a specific situation [4]. $K M$ aims to create value through keeping knowledge up to date and correct, providing informative data in the right location and delivering knowledge at the needed time. The white paper of Ricoh [3] states that knowledge workers spend at least $40 \%$ of every working day in processing information; approximately $80 \%$ of this information is unstructured, of which $90 \%$ is unmanaged; and $22 \%$ of the time is spent retrieving information (unsuccessfully $50 \%$ of the time, resulting in the recreation of existing information). Consequently, the real challenge today is not only dealing with the enormous amount of information, but also with the delivery of real-time information according to customer demand-driven. The lead time in finding the right information and the accuracy of the information together determine the result of decisions and thus have a direct impact on the success of an enterprise. Many approaches are in existence which consider personalization and adapt information supply to a user context in order to deliver $\mathrm{him} / \mathrm{her}$ appropriate information. It is a major issue to ensure optimal information supply with respect to the situations and individual demand of a user, and simultaneously prevent an information overload for mobile information services [5].

\section{Flows in Production Logistics}

Production logistics indicates the entire process of materials, data and products moving into, through, and out of a manufacturing firm. Inbound logistics covers the movement of materials received from initial suppliers, material management describes the movement of materials and components within a firm, and outbound logistics refers the physical distribution of finished goods from the end of assembly line to the customers. Basically there exist four types of flows between suppliers and customers in their production and distribution networks (see Fig. 1):

- Goods flows: the external logistics flows where transportation is predominant, and translation (storage) or transformation (value added logistics) may occur on the way. Depending on who manages which part of supply chain, the goods flow may be part of physical distribution for suppliers or part of physical collection for the customers.

- Transaction flows: these are generalizations of markets and sells, which are commercial distribution in view of suppliers and commercial supply in view of customers.

- Money flows: It is mainly payment for the goods received. There are time relationships among all the flows distinguished between suppliers and customers.

- Information flows: These are two way flows and usually there are a number of them related to each goods flow; closely related to transaction and money flows, in a sense that these flows are often transformed into information flows. Information may be transformed in time (storage and retrieving of information), space (telecommunication and electronic data interchange) or in form (data processing, computerized decision making and optimization) [6].

Modern production management is oriented towards automation and computer-integrated manufacturing, heavily relying on data flows as a controlled flow of materials producing information along with products and by-products (see Figure 2). The flow of goods and finances is represented in data base systems coordinating with the business transactions. Firms acquire data from external sources like government statistics, and share internally within the firms such 
as sales figures, employee records and manager reports. The top priority of data managers is to interlink management information systems with business goals and data utilization. The factory automation and its information strategies are current issues for information resource management and hence managers must rely on real-time data for statistical and fiscal control in optimizing production process [7].

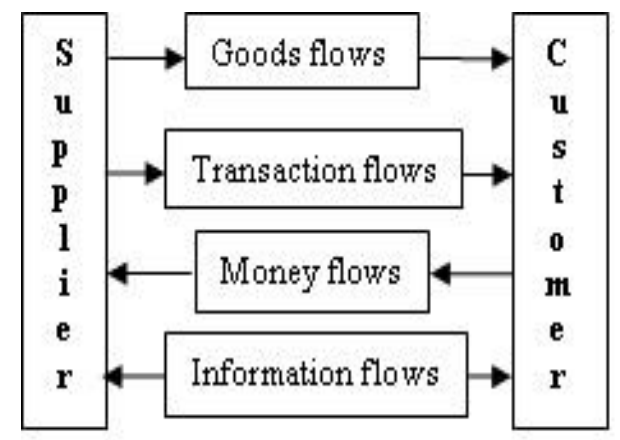

Figure 1: Production and distribution network flows

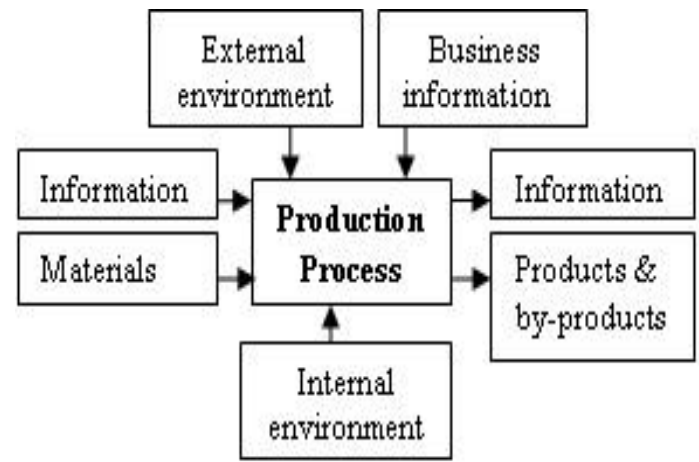

Figure 2: Basic production system model

\section{IT Enablers of Informed Logistics}

The rapid extension of $I T$ with more internet facility has created both impulsion and challenges to the logistics management. As a product management tool, $I L$ can be utilized to increase the capability and decrease the cost at the same time [8]. There are two lines of research in literature highlighting the role of information in logistics. The first relates to JIT logistics systems [9] [11]; while the second is the third party logistics [12] - [14]. In addition of various classifications in [15] - [19], Vaidyanathan [14] presented the categories of the physical and information flows between logistics functions (see Fig. 3), where flows are coordinated, managed and supported by various logistics technologies. Some of the $I T$ enablers are briefly explained below.

\subsection{Logistics Information System}

The logistics information system (LIS) plays a crucial role in shaping the direction of logistics management, which has become a significant managerial factor in production activities to enhance the capacities and accuracy of the logistics processes reducing both total lead time and inventory throughout production and distribution networks from suppliers to consumers [20]. An effective LIS facilitates the timely data flow between inventory, warehousing and transportation to realize the high level of customer service. The ability to optimize the logistics cost and service levels are affected by the LIS of the firm and its partners. Firms that provide better logistics services at a lower cost can have competitive advantage over its competitors [21]. Some of the benefits of adopting LIS are quick response, informed decisions, improved customer service, reduced paperwork, errors and manpower, tracing and controlling different logistics functions [22]. 


\subsection{Electronic Data Interchange}

The electronic data interchange $(E D I)$ is electronic exchange of business documents such as purchase orders, invoices, application forms etc. from one organization's computer to another organization's computer in standard data formats. It has successfully enhanced the communication between firms which is essential for logistics requiring firms to have common data formatting and transmission standards or protocols. It has been used by companies to coordinate their value chain logistics activities. Recent applications of logistics information carried by $E D I$ are purchase orders/releases and changes, advanced shipping notices, billings and invoices. Accurate and in-time EDI is crucial in decision making on complex logistics problems. Japan Airlines adopted EDI to manage their complex value chain logistics required for their operations, including procurement and JIT delivery of aircraft fuel, repair and maintenance aircraft parts, food catering and other customer requirements [23]. Companies utilizing EDI are better able to fulfill greater number of services to their customers [24].

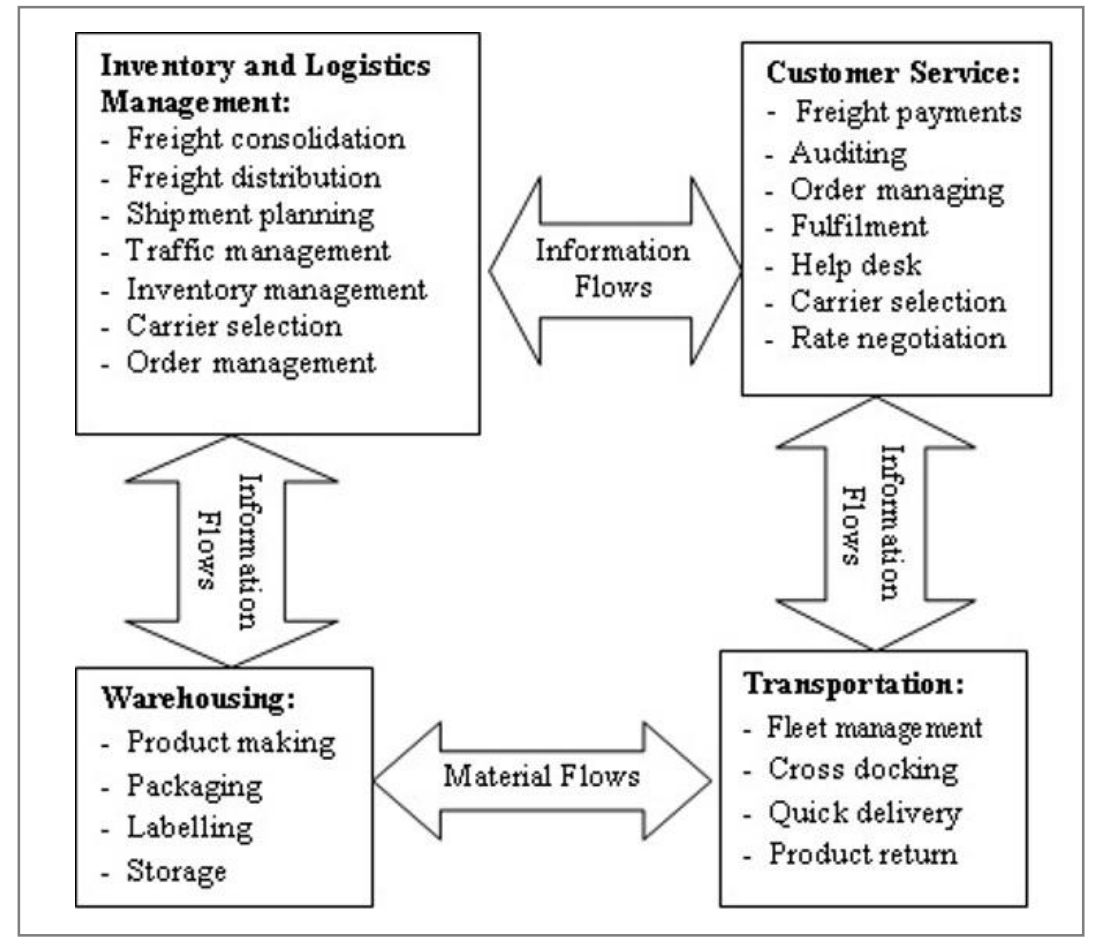

Figure 3: Logistics functions and information flows [14]

\subsection{Real-time Communication Capability}

The logistics capability of Real-time Communication Capability $(R T C)$ is essential to maintain the flow of information. LIS of business partners should have RTC capability to make real-time tracking of goods. The business partners require integrated messaging architectures which exchange business data while customizing business flows and format transformation. RTC allows for schedule plans to change in dynamic routing and scheduling system when the vehicles 
are already out on the road. Any last minute changes in routing and scheduling system or constant tracking has been possible only with $R T C$ of the systems.

\subsection{Bar Coding}

A bar code is a small image of lines, bars and spaces affixed to retail store items, identity cards and postal mails to identify a particular product number, person or location. Bar coding is a method of encoding data using bar code for fast and accurate readability. The bar code reader uses a laser beam that is sensitive to the reflections from the thickness of line, space and variation. The reader translates the reflected light into digital data that is transferred to a computer for immediate action or storage. Starting from 60s, some of the earliest implementations of bar codes were in rail road cars; but nowadays it is rampant in anything that needs to be identified and tracked. The different types of bar codes are available for different purposes. Most of the companies use industry standard bar codes on their products to reduce the complications inherent in the use of multiple standards and thus provide a strong foundation for integrating the corporate logistics and supply chain [25].

\subsection{Radio frequency identification (RFID)}

Radio frequency identification (RFID) enables services such as information exchange among objects, position tracking, remote processing and management by attaching electronic tags to objects, collecting and processing the data from the objects. It is an emerging technology intended to complement or replace traditional bar code system to track items automatically, which substantially reduces costs and time needed for inventory management. Dating back from 1940s, recently it is starting to make a significant impact within the supply chain. Among the companies that are piloting RFID in their supply chains, prominent ones are Wal-Mart, Procter and Gamble, Coca-cola and Gillette. In addition of supply chain, companies are experimenting it in other applications as well, such as theft detection, asset tracking, mobile payments, in-process inventory and luggage tracking. Dell, Boeing and Ford are among other companies that are using $R F I D$ to track their in-process inventory in manufacturing. An RFID system includes tags that can identify items; antennas that allows tags to be interrogated and to respond; and software that controls the RFID equipment, manages the data and interfaces with enterprise applications. It has lots of potential to improve the efficiency in the supply chain and reduce waste. For example, efficiency would result from automatic update of inventory system when products with $R F I D$ tags are unloaded from trucks into stores. Its use is expected to increase rapidly in coming years in various sectors.

\subsection{Global Positioning Systems}

The global positioning systems (GPS), a space-based global navigation satellite information system, enables firms in real-time tracking and performance monitoring of business operations keeping all the partners informed. Composed of space, control and user, it broadcasts signals from space that its receivers use to provide three-dimensional location (latitude, longitude and altitude) with precise time. It has been widely used as a useful tool for map-making, land surveying, commercial and scientific uses, tracking and overseeing; also it has become a mainstay of transportation systems worldwide, providing navigation for aviation, ground, and maritime operations. GPS ensures drivers and dispatchers stay connected, updating each other of 
important route and/or delivery information. This closed-loop communication helps business operations to perform smoothly and efficiently; better supporting drivers and customers. Other intelligent tracking technologies such as wireless communication and geographical information system are also effective for improvements in service, and efficiency can be enhanced throughout the supply chain.

\section{New Approaches of $I L$}

\section{$5.1 \quad$ ABSO Model}

A new perspective of $I L$ in managing information is to create unique value through smart and coordinated systems. The operational priorities must be shifted from spending money on information to making money from information. Slightly differing from Ricoh's $A C B O$ model [3], our new approach to handle raw data as systematic information in production logistics includes four phases of information: Alerting (awareness), Building, Sharing among partners and Operating in production systems; to which we call ABSO information model (see Fig. 4). Effectively and efficiently managing and sharing of public sector information has the power to satisfy customer demand, improve society and drive economic growth of nation as a whole. Good governance, professionalism and dynamism in knowledge and information management are the key elements both to capture opportunities and to meet the challenges ahead. Quality information is needed on overall costs and consequences to make informed decisions and operations. The $A B S O$ model converts data into information and then to knowledge in accelerating the informed flow for customers to increase their flexibility and reduce costs, where the level of info-hierarchy is: data $\rightarrow$ information $\rightarrow$ knowledge $\rightarrow$ intelligence. Effective supply chain practice and information sharing enhance the current supply chain management environment which is an interconnected system (see Fig. 5).

\subsection{Real Time Model of $I L$}

Consider $n$ number of data with demands $d_{1}, d_{2}, \cdots, d_{n}$ in time slot 1 through $T$ at production stage $s, s=1,2, \cdots, S$ such that the total demand of information is $D=\sum_{i=1}^{n} d_{i}$. Let $I L_{e t}^{i}$ be the expected informed logistics in stage $s$ at time $t$ and $I L_{a t}^{i}$ be the actual informed logistics gained at the same stage and time. Then objective of real time informed logistics $(R T I L)$ is to minimize the variation between $I L_{a t}^{i}$ and $I L_{e t}^{i}$, which is formulated as

$$
\begin{aligned}
& (R T I L): Z_{\min }=\min \sum_{t=1}^{T} \sum_{i=1}^{n}\left|I L_{a t}^{i}-I L_{e t}^{i}\right| \\
& \text { s.t. } \sum_{i=1}^{n} I L_{a t}^{i}=T \quad t \in T, s \in S .
\end{aligned}
$$

The constraint (2) states that actual data must be received within the time bound. The minimum RTIL deviation helps to reduce delays on being informed and delays on the movement of logistics goods along with the supply chain. 


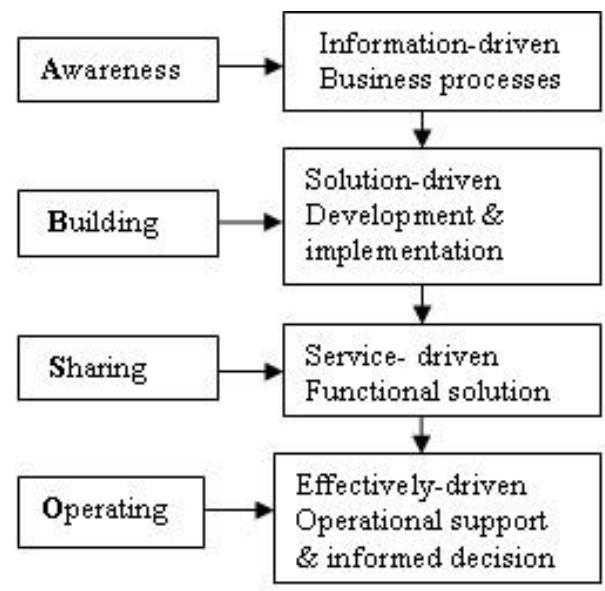

Figure 4: ABSO information model

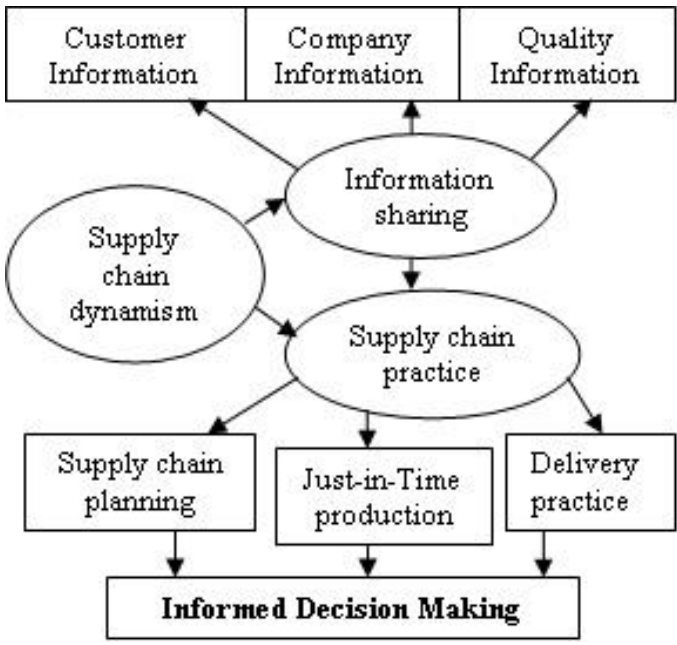

Figure 5: Information sharing model in supply chain

\subsection{Applications in Real-Time Scheduling Problems}

The IL plays a crucial role to solve the real-time scheduling problems by feeding reliable and quality information in $J I T$ environment, for example product rate variation problem $(P R V P)$ and response time variability problem $(R T V P)$ are the two, among others. The $P R V P$ is the sequencing of products in mixed-model assembly line intending to find a balanced sequence of different models of same product, where each model is distributed as evenly as possible satisfying demands for different models. If we consider three models $a, b, c$ of a same base product with the integer demands 4,2,2 respectively, then one of the feasible mixed-model sequences of the models is $s=$ (abacabac). Such sequences reduce shortages and inventories [26], minimizing the maximum and the total deviations between actual and desired productions. For mathematical models of PRVP to be solved for fair sequences in real-time, we refer [27] [29]. These sequences will be more feasible and optimal when provided the valuable information on parts compatibility and alerting operators/supervisors well before errors occur. The RTVP is a combinatorial optimization problem, recently developed in [30] to model a broad range of reallife situations that occurs when customers, jobs, events or products need to be sequenced to minimize the variability of the time that they wait for their next turn in obtaining the resources they need to advance. The idea of fair sequences firstly appeared at Toyota in sequencing of mixed-model assembly lines under JIT production systems. That is, RTVP is designed to minimize variability in the distance between any two consecutive copies of the same models. The mathematical formulation of RTVP is modeled as follows:

Let $n$ be the number of products or jobs, $d_{i}$ be the number of copies of the model $i$ to be scheduled such that $i=1,2, \ldots, n$, and $D$ be the total number of copies such that $D=\sum_{i=1}^{n} d_{i}$. Let $s$ be a solution of an instance of RTVP consisting of a circular sequence of copies $(s=$ $\left.s_{1} s_{2} \ldots s_{D}\right)$, where $s_{j}$ is the copy sequenced in position $j$ of sequence $s$. For each model $i$ $\left(d_{i} \geq 2\right)$, let $t_{i k}$ be the distance between the positions in which copies $k+1$ and $k$ of model $i$ are found, where the distance between two consecutive positions is considered to be 1 . Since $s$ is circular, position 1 comes immediately after position $D$; so $t_{i d_{i}}$ is the distance between the first 
copy of model $i$ in a cycle and the last copy of the same model in the preceding cycle. Let $\overline{t_{i}}$ be the desired average distance between two consecutive copies of model $i$ such that $\overline{t_{i}}=\frac{D}{d_{i}}$. Note that for each model $i$ in which $d_{i}=1, t_{i 1}$ is equal to $\overline{t_{i}}$. The goal is to minimize the metric, called response time variability $(R T V)$, defined by the sum of the squared deviations with respect to the $\overline{t_{i}}$ distances. This objective is defined by the following expression:

$$
\mathrm{RTV}=\sum_{i=1}^{n} \sum_{k=1}^{d_{i}}\left(t_{i k}-\overline{t_{i}}\right)^{2}
$$

Note that RTV metric (1) is a weighted variance with weights equal to $d_{i}$; expressed as

$$
\mathrm{RTV}=\sum_{i=1}^{n} d_{i}{ }^{*} \operatorname{Var}_{i}, \text { where } \operatorname{Var}_{i}=\frac{1}{d_{i}} \sum_{i=1}^{d_{i}}\left(t_{i k}-\overline{t_{i}}\right)^{2}
$$

$R T V P$ is shown $N P$-hard in [30], giving a dynamic program and a mathematical program for finding optimal solutions. Some heuristics and meta-heuristics are used to solve RTVP as recent approaches, for which timely information flow is a determining factor.

\section{Conclusion}

The $I L$ forms a part of series of activities that is aimed to address the societal challenge. It is concerned with how we can move people, money, goods and information more intelligently throughout the whole logistics supply chain. There are many funding opportunities on $I L$ in the market for balanced use of technology with an understanding of human behaviour. Information partnership can help firms to gain access to new customers and creating new opportunities for cross-selling products. Capturing and managing digital information and keeping them useable are today's key issues for production industries. The role of $I L$ is equally crucial in the environment-friendly sustainable green logistics.

\section{References}

[1] Lambert, D. M., and Stock, J. R. (1993). Strategic logistics management, $3^{\text {rd }}$ edition, Irwin, Homewood.

[2] Willems, J. (2008). From having to using, NRI Working paper series, 8.

[3] Ricoh Europe plc. (2009), Information Logistics - Achieving performance - and satisfied customers, White paper on future customer needs.

[4] Lee, C. C. and Yang, J. (2000). Knowledge Value Chain, Journal of Management and Development, 19(9), 783-793.

[5] Meissen, U., Voisard, A. and Wahnfried, T. (2005). Resolving knowledge discrepancies in situation-aware systems, Journal of Pervasive Computer \& Communication, 1(4).

[6] Tilanus, B. (1997). Information Systems in Logistics and Transportation, $2^{\text {nd }}$ edition, Pergamon Press.

[7] Boggs, R. A. (1990). Production information systems: Practical considerations and concerns for information resources management, Journal of Information Technology Management, I (1), 23-28.

[8] Closs, D. J., Goldsby, T. J. and Clinton, S. R. (1997). Information technology influences on world class logistics capability, International Journal of Physical Distribution \& Logistics Management., 27(1), 4-17.

[9] Schwarz, L. B., and Weng, Z. K. (2000). The design of a just-in-time supply chain: The effect of lead time uncertainty on safety stock, Journal of Business Logistics, 21(2), 231-252.

[10] Takahashi, K., and Nakamura, N. (2000). Reactive logistics in a just-in-time environment, Production Planning \& Control, 11(1), 20-31. 
[11] Lai, K. H., and Cheng, T. C. E. (2009). Just-in-Time Logistics, Gower Publishing Ltd., England.

[12] Lewis, I. and Talalayevsky, A. (2000). Third-party logistics: Leveraging information technology, Journal of Business Logistics, 21(2), 173-185.

[13] Sauvage, T. (2003). The relationship between technology and logistics third-party providers", Int. Journal of Physical Distribution \& Logistics Management, 33(3), 236-253.

[14] Vaidyanathan, G. (2005). A framework for evaluating third-party logistics, Communications of the ACM, $48(1), 89-94$.

[15] Bowersox, D. J. (1974). Logistics management: A systems integration of physical distribution management and materials management, Macmillan Publishing, NY.

[16] Ballou, R. H. (1976). Computer methods in transportation - distribution, Transportation Journal, 16(2), $72-85$.

[17] House, R. (1978). Computer models in distribution management, Journal of Business Logistics, 1(1), 129152.

[18] Stenger, A. J. (1986). Information systems in logistics management: past, present, and future, Transportation Journal, 26(1), 65-82.

[19] Novack, R. A., Rinehart, L. M. and Wells, M. V. (1992). Rethinking concept foundations in logistics management, Journal of Business Logistics, 13(2), 233-267.

[20] Lai, K. H., Ngai, E. W. T. and Cheng, T. C. E. (2005). Adoption of information technologies in Hong Kong's logistics industry, Transportation Journal 44 (4), 1-9.

[21] Bardi, E., Raghunathan, T. and Bagchi, P. (1994). Logistics information systems: The strategic role of top management, Journal of Business Logistics, 15(1), 71-85.

[22] Ngai, E. W. T., Lai, K. H. and Cheng, T. C. E. (2008). Logistics information systems: The Hong Kong experience, International Journal of Production Economics, 113, 223-234.

[23] Chatfield, A. T. and Andersen, N. B. (1997). The impact of IOS-enabled business process change on business outcomes: Transformation of the Value Chain of Japan Airlines, Journal of Management Info. Systems, 14(1), 13-40.

[24] Rogers, D. S., Daugherty, P. J. and Stank, T. P. (1992). Enhancing service responsiveness: the strategic potential of EDI, International Journal of Physical Distribution and Logistics Management, 22(8), 15-20.

[25] Closs, D. J. and Kefeng, X.(2000). Logistics information technology practice in manufacturing and merchandising firms: An international benchmarking study versus world class logistics firms, International Journal of Physical Distribution \& Logistics Management, 30(10), 869-86.

[26] Monden, Y. (1983). Toyota Production Systems: Practical Approach to Production Management, Industrial Engineering and Management Press, Norcross, GA.

[27] Thapa, G. B., and Dhamala, T. N.(2009), JIT sequencing in mixed-model production systems relating with fair representation in apportionment theory, The Nepali Mathematical Sciences Report, 29(1 \& 2), 29-68.

[28] Thapa, G. B., Dhamala, T. N. and Yu, H. (2012). An efficient frontier for sum deviation just-in-time sequencing problem via apportionment, International Journal of Automation and Computing 9(1), 87-97.

[29] Miltenburg, J. (1989). Level schedules for mixed-model assembly lines in just-in-time production systems, Management Science, 35, 192-207.

[30] Corominas, A., Kubiak, W. and Moreno, N. (2007). Response time variability, Journal of Scheduling, 10(2), 97-110. 